Indonesian Journal of EFL and Linguistics

Vol. 6 No. 1, 2021

eISSN: 2503-4197, pISSN: 2527-5070

www. indonesian-efl-journal.org

doi: http://dx.doi.org/10.21462/ijefl.v6i1.344

\title{
A Genre Analysis of Bachelor of Arts in English' Undergraduate Theses
}

\author{
Runalyn O. Arnaiz \\ Cebu Technological University, Philippines \\ Lorlie Colagbang \\ Cebu Technological University, Philippines \\ Maria Regla Inoc \\ Cebu Technological University, Philippines
}

Ailene Torregosa

Cebu Technological University, Philippines

\author{
Rowanne Marie Maxilom-Mangompit \\ Cebu Technological University, Philippines \\ e-mail: rowannemarie.mangompit@ctu.edu.ph
}

\begin{abstract}
:
Research Article (RA) is one of the most important genres that received considerable attention in genre analysis. This study sought to investigate the rhetorical structures of $R A$ abstracts written by AB-English students of Cebu Technological University. This investigation used Hyland's (2000) framework which includes: Introduction, Purpose, Methodology, Product, and Conclusion. This paper utilizes qualitative approach where a total of fifteen abstracts were selected from Cebu Technological University. The corpus of abstracts written by AB-English students were randomly selected from the CTU graduate library. The researchers found out there were no instances of Introduction move found in the abstracts. The purpose move constituted the fourteen (14) abstracts in the undergraduate theses written by AB-English. Fourteen (14) studies included the method move in their
\end{abstract}


Runalyn O. Arnaiz, et al

research abstracts. Fourteen out of fifteen studies included the product move and thirteen (13) instances of conclusion move were found in the abstracts. The researchers concluded that the abstracts followed the commonly-applied three moves such as purpose, methodology and product. The results demonstrated that the research topics on phonology, morphology, and purposive communication were already widely-explored by the student researchers. There was a dearth of research topics related to multimodal communication, child and adolescent learners and learning principles. Therefore, this study provides implications to writing research abstracts and topics that need to be explored in the undergraduate theses writing.

Keywords: Genre analysis, introduction section, moves, undergraduate theses

\section{INTRODUCTION}

Research Article (RA) is one of the most important genres that received considerable attention in genre analysis. A number of previous studies have focused on analyzing the organizational patterns of RA sections in terms of moves such as analyzing the introduction, method, and the results and discussion sections. Research abstracts have gained extreme importance due to the huge academic information in the world. Abstracts are seen as the readers' doorway to view an article, journals' selection for contributions, and conferences in evaluating articles (Li, 2011). Therefore, recent research articles are more likely to be accompanied by more informative abstracts that would enable them to get acceptance to internationallyrecognized journals. The prior studies have focused more on various disciplines such as medicine, engineering, and psychology.

However, there is a need for more genre analysis that compares RA abstracts in the field of Applied Linguistics. This study attempted to analyze the abstracts written by other researchers to get ideas and information about the research abstract structure and the way of writing it. This could lead to lack of creativity, critical thinking, subjectivity, and innovation ns (Abarghooeinezhad \& Simin, 2015). The wellknown abstracts would attract more readers and enhance the opportunity of these abstracts to be indexed and cited in internationally-recognized journals [10]. Studies on genre analysis have used a framework of RA abstracts containing the Introduction, Methods, Results, and Discussion (IMRAD) to analyze the RA abstracts. The organizational pattern of the moves, grammatical structures, and literary features that formulate these moves and steps were the subject of studies in research article abstracts.

Many studies have been published around the world every year, and RA abstracts have become an important element to assist readers in select appropriate readings for them. However, RA abstracts square measure totally different from RAs in 3 
aspects: perform rhetorical structure, and linguistic realizations (Kosasih, 2018). Due to that difference, a number of analyses have been conducted to determine the textual organization of RA abstracts. This organization includes: the macro-level features of textual organization, and micro-level features at the sentence level (Lorés, 2004). Some of these studies used the model of 5 moves that included: situating the analysis (M1), presenting the analysis (M2), describing the methodology (M3), summarizing the results (M4), and discussing the research (M5). The results of these studies concluded that M2 and M3 were essentially compulsory moves in the genre, and the other moves required different linguistic resources to realize theme, tense choice, and voice choice (Bhatia, 1997).

A more elaborate model which has been influential for lots of studies is Hyland's [8] model of RA abstracts. It includes five moves: Introduction, Purpose, Method, Product, and Conclusion (IPMRC) - the five-move framework to identify the rhetorical structure of the selected corpus (Kosasih, 2018). According to this framework, five moves are involved: Introduction (M1), Purpose (M2), Method (M3), Product (M4), and Conclusion (M5). Each move represents the realization of a communicative purpose. In contrast to the other models, this model distinguished the writer's purpose from the introduction move, where it is often located (Kosasih, 2018). Table 1 below presents the linear order five-move model [9].

Table 1. Hyland's five-move model

\begin{tabular}{|l|l|}
\hline Moves & Functions \\
\hline Introduction & $\begin{array}{l}\text { Establishes context of the paper and motivates the research or } \\
\text { discussion. }\end{array}$ \\
\hline Purpose & $\begin{array}{l}\text { Indicates purpose, thesis or hypothesis, outlines the intention behind } \\
\text { the paper. }\end{array}$ \\
\hline Method & $\begin{array}{l}\text { Provides information on design, procedures, assumptions, approach, } \\
\text { data, etc. }\end{array}$ \\
\hline Product & $\begin{array}{l}\text { States main findings or results, the argument, or what was } \\
\text { accomplished. }\end{array}$ \\
\hline Conclusion & $\begin{array}{l}\text { Interprets or extends results beyond scope of paper, draws inferences, } \\
\text { points to applications or wider implications. }\end{array}$ \\
\hline
\end{tabular}

\section{LITERATURE REVIEW}

In the following sections of this paper, a brief review of research article as a genre and research article abstract as a part of genre are introduced. Most of the studies have addressed the research article abstracts' rhetorical structures in terms of its moves. Some related studies analyzing research article abstracts are presented.

An elaborate model which has been influential for lots of studies is Hyland's model of RA abstracts. It includes five moves: Introduction, Purpose, Method, Product, and Conclusion (Hyland, 2000). 
The reviewed studies analyzed various fields who focused on the Iranian journals of Applied Linguistics (Behnam, \& Golpour, 2014), textual organization of research article abstracts, and the abstracts of Engineering, Finance and Surgery (Candarh, 2012). Other studies focused on linguistics, applied linguistics (Behnam, \& Golpour, 2014; Pho, 2009), abstracts of students' theses of a State University with varied disciplines, abstracts of ESP, psycholinguistics, and sociolinguistics and literature (Hyland, 2000; Magno et al, 2020).

First, a study of Behnam, \& Golpour, (2014) was conducted to help ESL, EFL and EAP teachers instruct their novice students about schematic pattern and utilize this model in their research abstract writing. 40 RA abstracts published between 2008 and 2013 were randomly selected from an international and Iranian journals of Applied Linguistics and Mathematical Studies. Following Hyland's (2000) model, the results show that the purpose move (M2), the method move (M3) and the product move (M4) are the most frequent and obligatory moves in both groups of abstracts. In contrast, the other two moves, the introduction move (M1) and the conclusion move (M5) occur less frequently. As study found similar pattern for the research article abstracts: PMRC (Mohammadi, 2016).

This study explored the rhetorical and grammatical features of research article abstracts. The corpus was consisted of three groups from three credited international journals. Each group contained 21 abstracts and nine research article abstracts were piloted. He found out that the most frequent move pattern turned out to be PMRC (Purpose, Method, Results, Conclusion) in all three groups. The introduction move was concluded as a common feature that was mainly embodied with topic generalizations. On the other hand, conclusion move was most often viewed as gathered from results.

The textual organization of research article abstracts at two levels such as the features that constitute abstracts at the macro-level of textual organization, and the sentence level features at the micro-level of textual analysis were also explored (Santos, 1996). 94 research article abstracts from the field of applied linguistics were selected as the corpus for his analysis. Santos found out that M2 and M3 were obligatory moves in the genre, and different moves required different linguistic resources to realize their purposes.

Third, A Chinese study on the discourse structures and linguistic features in three fields (engineering, finance and surgery) was conducted using a 5-move model. The results showed that most of the abstracts followed the same move sequence. In a comparative study of research article abstracts, similar pattern for the research article abstracts which is the PMRC (Purpose, Methods, Results, Conclusion) was found (Samraj, 2005)

Fourth, a genre analysis on a corpus of thirty-six RA abstracts in the linguistics field was carried out (Pho, 2009). The findings of her study revealed that the majority of 
the abstracts (61\%) followed the IMRAD model, followed the CARS model (31\%), and showed employment of the two models (8\%). Also, three RA abstracts functions were inferred: the indicative, the informative, and the informative-indicative function. The results of this study might explain why previous studies were not consistent in terms of rhetorical organizations of abstracts and the inflexible description of the abstracts' organization. This study is similar to the present study in analyzing the abstracts.

Fifth, another genre analysis of research article abstracts of 20 abstracts written by native and non-native speakers of English in the Applied Linguistics field was conducted (Behnam, \& Golpour, 2014). The abstracts were selected from wellknown journals in Applied Linguistics. The model of genre analysis (Candarh, 2012). was employed to explore the differences between native and non-native writers in rhetorical structure of research abstracts. The results of the study revealed that both native and non-native writers followed the rhetorical structure of three moves (Purpose, Method, and Conclusion), while there was a significant difference between those writers in the introduction and conclusion moves.

Sixth, Fauzan, Lubis \& Kurniawan (2020), investigated the rhetorical moves and linguistic complexity of research articles of abstract in the four Applied Linguistics journals. Using the qualitative research method and Hyland's (2000) moves, the results showed the evidence of commonly-used moves such as purpose, method and findings. Introduction was only used optionally as demonstrated in the data. Although there were only few journals analyzed, this study was relevant in the present study with the predominant moves evident in the data.

Seventh, a study identified the move structure of English abstracts of students' thesis of a State University and identified the preferred verb tense used of each move in the English abstracts of the students' thesis (Li, 2011). This study employed qualitative case study. 40 English abstracts from varied disciplines were collected and analyzed. This study revealed that the A-M-R (Aim-Method-Result) move structure was the most frequently-used abstract move structure used in every discipline across the four disciplines with proportion. The present tense and past tense are used in each move across the four disciplines.

The eighth empirical study on the move structures and personal pronouns of fifty English RA (research article) abstracts was conducted and revealed that three other move patterns were ascertained besides ten out of the analyzed abstracts following his move order (Pho, 2009). The analysis of personal pronouns showed that firstperson plural pronouns were used far more frequently than other types of personal pronouns. There was an absence of the second-person and the third-person pronouns were detected in the abstracts. A further analysis suggests that first-person plural pronouns can perform multiple functions in abstracts. ESP (English as Special Purpose) teachers may benefit from the study to guide students to explore the discourse conventions of the RA abstracts in their own texts. 
Ninth, an analysis of research article introductions from three related fields, ESP, psycholinguistics, and sociolinguistics, using Swales' CARS model (Lorés, 2004). The corpus consisted of 90 RAs drawn from a wide range of refereed journals in the corresponding disciplines. The results of the analysis, although revealing marked differences across the disciplines regarding Move 2/step 1B, indicate no marked differences in research article introductions across the disciplines in terms of Move 1 and 3 along with their constituent steps. Furthermore, no marked differences were found in terms of the extent of concordance between the CARS model and the move structure of the RAs analyzed. The results also underlined the need for further research into the CARS model and provision of a more flexible and open-ended structure, one which is pattern-seeking rather than pattern imposing and provides the writer/researcher with the necessary options for the inclusion of further steps, one in which free-standing steps are not assigned rigid functions and positions in the overall structure but are multi-functional or multi-purpose and can be shuffled in the overall structure.

The tenth empirical study was on the cohesion of the introduction section of introduction section of research abstracts (Rochma \& Triyono, 2019). These abstracts were taken from the 112 undergraduate theses of students in English language teaching. With the use of qualitative research method, the findings showed the scarcity of lexical cohesion in the students' abstracts. Even though the data of these study were from the undergraduate theses which were similar to the present study, the focus of the reviewed study was on the lexical cohesion.

Lastly, following the rhetorical moves on genre analysis, studies on different sections of RAs in various languages and fields abound; however, only scant attention has been directed toward abstracts written in Persian, and in the field of literature. Moreover, claims made regarding the correspondence of two types of abstracts with different models (Pho, 2009). To fill this gap, 90 English and Persian abstracts written in the field of literature, by English and Persian native speakers, were analyzed based on the IMRD (Introduction, Method, Results, and Discussion) and CARS (Create A Research Space) models. The results demonstrated that literature RA writers generally focused on Introduction and Results, neglect Method and Discussion, and did not mention the niche in previous related work. Although none of the models were efficient, literature abstracts generally matched CARS more than IMRAD and the abstracts written by Persian native speakers had minor deviations from both the Persian and the international norms, and exhibited a standard of their own. The present study also discussed the steps which the models fail to predict. In addition, it offers a number of pedagogical implications for TEFL, especially for the writing skill.

The current study is rather similar in using the same framework of analysis. However, this study focused on the AB-English students who are non-native speakers of English. The present paper were similar with the reviewed studies in 
terms of purpose but this study focused on one particular discipline or field which is the applied linguistics. Previous researches differentiated the introductions of research article abstract but this paper focused on the moves used in writing research abstracts.

However, to the best of researcher's knowledge, there were no studies that compared rhetorical features of Applied Linguistics in Cebu Technological University. Also, there were no compared and contrasted move structures of abstract section written by Applied Linguistics students. Most of the linguistic students seem unaware of the standard conventions and the importance of abstracts in academic writing. Therefore, there was a need to conduct a study to help linguistic students to gain academic writing patterns and conventions by providing them with necessary information to be able to read and write research abstracts and to receive the latest contributions, as well as publishing English articles in the field of Applied Linguistics.

This study analyzed the research article abstracts of AB-English students for Academic Year 2017-2018 of Cebu Technological University-Main Campus. Specifically, this study sought to answer the following statements: (1) commonly used Moves in Research Article Abstracts based on Hyland's (2000) theory; Introduction, Purpose, Method, Product, Conclusion (2) descriptive courses that are frequently manifested based on the official prospectus of Bachelor of Arts in English Language (Candarh, 2012).

\section{RESEARCH METHODOLOGY}

\subsection{The Corpus}

This paper used the descriptive research method where fifteen abstracts were selected from Cebu Technological University undergraduate theses in 2018. The corpus of abstracts written by AB- English students were selected through purposeful random sampling from the CTU graduate library. The selected abstracts were published on the academic year 2017-2018. The abstracts were produced for various topics of the applied linguistics field. Both journals were available on the library and were all checked in terms of the author's validity and reliability.

\subsection{Research Instrument}

The present study used the completed undergraduate theses of the Bachelor of Arts in English major in Applied Linguistics in 2018 where the abstracts were also included in the paper. A checklist was used in coding and analyzing the moves indicated in the Hyland's (2000) theory.

\subsection{Data Analysis}

The analysis of written texts involves examining the rhetorical structure of the selected abstracts. According to Ackland (2009), there are two methods in recognizing and setting move borders, one was based on "top down" approach and 
"bottom-up approach. In this study, the content of the abstract is examined and identified using the "top-down" approach. Following Hyland's (2000) model, the frequency of each move in each abstract was calculated. The recognition of each move in the data sets was quite straightforward on the whole.

The aligned descriptive courses discussed in the abstracts were also analyzed and recorded to measure how these topics frequently appeared on researches. The frequency of the compared research topics was illustrated based on based on the ABEnglish A.Y. 2018 prospectus.

\section{FINDINGS}

This section presents the results obtained from this study. It starts with presenting the frequency of the occurrences of moves in the abstracts written by AB-English students.

Table 2. Frequency of the occurrence of the abstracts' moves

\begin{tabular}{|l|c|}
\hline \multicolumn{1}{|c|}{ Moves } & f \\
\hline Move 1: Introduction & 0 \\
Move 2: Purpose & 14 \\
Move 3: Method & 14 \\
Move 4: Product & 14 \\
Move 5: Conclusion & 13 \\
\hline
\end{tabular}

Table 2 demonstrated the predominance of purpose, method and product in the abstracts of the undergraduate theses together with the evidence of conclusion. However, there was an absence of introduction in the data understudy.

Table 3. Research Topics

\begin{tabular}{|l|c|}
\hline Course Descriptive Title in the Prospectus & f \\
\hline Purposive Communication & 11 \\
English Phonology and Morphology & 11 \\
Semantics of English & 7 \\
English Discourse & 7 \\
Theories of Language and Language Acquisition & 7 \\
Introduction to Language, Society and Culture & 7 \\
Introduction to the English Language System & 6 \\
ELT Approaches and Methods & 5 \\
English Syntax & 4 \\
Language of Non-Literary texts & 4 \\
History of the English Language & 2 \\
Foundations of English Language Studies & 2 \\
Multimodal Communication & 1 \\
Language of Literary texts & 3 \\
The Child Adolescent Learners and Learning Principles & 0 \\
\hline
\end{tabular}

Table 3 illustrates the research topics based on the AB-English A.Y. 2018 prospectus. The research article abstracts were also analyzed according to its different descriptive course title in the prospectus of the Cebu Technological 
University Main Campus' prospectus of the AB English major in Applied Linguistics program. This was done by analyzing at the purpose and findings of each research abstracts.

As shown in the Table 3, eleven abstracts focused on the English Phonology and Morphology, Purposive Communication. Seven abstracts dealt with the Introduction to English Language, English Discourse, Semantics of English and Theories of Language and language acquisition. These topics could be attributed to the topics commonly-explored by the undergraduate thesis writers and supported by the mentors in language teaching.

\section{DISCUSSION}

This section discusses the results of the study. As indicated in Table 2, the purpose move (M2), the method move (M3), and the product move (M4) were the most frequently moves occurred in the abstracts written by both AB-English students. However, the introduction move (M1) and the conclusion move (M5) occur less frequently. This is obvious that not all authors follow the conventional structure of abstracts. Next section presents the results of each abstract move in details.

\section{Move 2- Purpose}

The purpose move is employed to present the purpose of the study. The purpose of the study is classified into two forms: the descriptive form that focuses on presenting the features of the research, or the purposive form that uses some expressions like "the aim" or "this study". The purpose move constitutes the fourteen (14) abstracts written by AB- English. Examples of this move are shown below:

"This study described the linguistic features employed in the undergraduate thesis manuscripts of Cebu technological University-Main Campus during the academic year 2014-2015." (Abstract 1)

"This study assessed the influence of $O B E$ on the speaking performance of BSIT Automative freshmen as to content, diction and fluency during the first semester of the AY 2017-2018." (Abstract 3)

As illustrated above, most of the authors followed the same sequence of writing the abstracts. The AB English students revealed a preference to begin their research abstracts with the purpose move. These findings are in line with the previous study by Zhen ye (2008)that indicated that all the abstracts included the purpose move. This implies that the purpose move is a compulsory step in the Applied Linguistics abstract genre (Zhen, 2008)This aim or purpose was also predominantly employed in analyzing the forty English abstracts with various disciplines (Kosasih, 2018).

Move 3- Method

The method move was used by authors to describe the mechanism of conducting their research by presenting the population and sample, materials and instrument, 
Runalyn O. Arnaiz, et al

research procedures, and the design of the study. In the present study, fourteen studies included the method move in their research abstracts. Examples of this move are as follows:

"This study used descriptive-qualitative method to determine the significant relationship between the respondent's competence and their language affects." (Abstract 4)

"Descriptive qualitative method with the use of audio-recorded interview and individual follow-up survey is used." (Abstract 5)

These findings concur with these findings (Magno et al, 2020). who reported that almost all the analyzed abstracts contained the method move. Again, this move is an obligatory move in any research abstract and it would be very difficult to understand the research if this move is missing [Magno et al, 2020; )., 9].

\section{Move 4- Product}

The product move is used to briefly present and summarize the major results of the study. It might also include the arguments or description of the achieved research objectives. Fourteen out of fifteen studies included the product move in their research abstracts. Examples of this move are as follows:

"The findings of the study reveal that the dominant English speakers are highly proficient with the pronunciation features while the dominant Cebuano speakers are poor in aspiration; highly proficient in stressing; and moderately proficient in vowel lengthening. The findings of the study also reveal that there is a significant relationship with the dominant English and Cebuano speakers' language profile and their performance in the following pronunciation features specifically order or dominance with a significant relationship to aspiration and vowel length, and fails to reject stressing." (Abstract 9)

"Based on the gathered data, the following findings were revealed (1) as for the level of the respondents' speech performance, majority of the respondents are rated "satisfactory" in terms of the three mechanics in speaking accuracy, fluency and comprehension (2) As for the most used speech repair, majority of the students used an abridged repair (3) There is a significant correlation between the respondents' level of speech performance and the speech repairs." (Abstract 11)

These findings coincide with the previous studies' [Habibi, 2008); Pho, 2009] findings who reported that all the studied abstracts included the product move. It is believed that the product move occurs in all research abstracts to "sell" and promote their research to the community of the same field (Mohammadi, 2016). 
A Genre Analysis of Bachelor of Arts in English' Undergraduate Theses

Move 5- Conclusion

The conclusion move is employed by writers to make their claims about the research and summarize the implications drawn from the results. In the present study, thirteen (13) instances of move 5 were found in the abstracts written by AB English students. Examples on this move are as follows:

"Based on the findings of the study, syntactic, morphological and semantic analyses were used to determine the lexicons, morphological processes and cultural influences in Iniskaya written documents. Furthermore, knowledge of the structures of Iniskaya language would help preserve the endangered language." (Abstract 13)

"It is concluded that the paravocalic behaviour (sic) of a speaker facilitates a bigger counterpart of the meaning of a message rather than its literal content as supported by Howard Giles' Communication Accommodation Theory." (Abstract 14)

These results in line with the results of the study who found that Chinese authors used the conclusion move so much less compared to the native writers of research abstracts (Hyland, 2000). This could be attributed to the awareness that native speakers hold about the importance of the conclusion move, and its essential role for scholars planning to conduct research in the same field. Non-native writers may believe that their research papers are well-organized and no need for conclusions to attract the interested readers in this field (Hyland, 2000). The predominance of conclusions was also supported in the study that analyzed the abstracts of Applied Linguistics, Mathematics and Chemistry.

Further, Al-Khasawneh, Fadi Maher (2017) and Fauzan, Lubis \& Kurniawan (2020) also supported the findings as they discovered that both native and non-native writers followed the moves such as purpose, method, and Conclusion. However, the native writers employed the introduction and conclusion eagerly compared to the non-native writers (Al-Khasawneh (2017) while Fauzan, Lubis \& Kurniawan (2020) only considered the introduction move optional.

Moreover, in the study of Behnam, \& Golpour (2014), the writers in Applied Linguistics adhered to the conventions of rhetorical moves compared to those writers of Mathematics. This result implies the discipline could be a factor of the variations in demonstrating the rhetorical moves in abstract writing.

Concerning the findings on the research topics, the results suggest that the research topics on phonology, morphology, and purposive communication were already widely explored by the student researchers. However, the results of this study contradicted with the previous study that found phonology and morphology as not much explored topics (Magno, Mangompit \& Cacha, 2020). There was a dearth of

Indonesian Journal of EFL and Linguistics, 6(1), 2021 
Runalyn O. Arnaiz, et al

research topics related to multimodal communication, child and adolescent learners and learning principles due to lack of experts in Linguistics.

\section{CONCLUSION}

The present study aimed at analyzing the research article abstracts written by ABEnglish (2018) students. The findings of this study revealed commonly-used moves in writing their research abstracts. The AB English students did not literally follow the international convention of academic discourse community. The language students did not use the Introduction move in writing while the Conclusion move was included frequently.

The findings of the present study could help the language students in particular with their academic writing. The improvement of genre knowledge would help novice writers in becoming active members in their disciplinary community (Candarh, 2012). The importance of genre analysis is in providing useful information to writers by exposing them to a particular genre convention (Behnam, \& Golpour, 2014). The findings might also be a guide for writers in realizing the textual variations in terms of moves, moves' sequence, and the role of each move in the research abstract. In addition, the findings obtained from this study help students to better understand the development occur in the Research Article abstracts in the Applied Linguistics field both linguistically and structurally. Through this awareness, English Language students will improve their opportunities to publish their research in internationallyrecognized journals and discourse communities.

Based on the findings and conclusions, future researchers are encouraged to apply the conventional format of writing abstract papers and must follow the five moves framework where in abstracts should have an introduction, purpose, method, findings and conclusion. Moreover, the researchers of this study suggests to future researchers to have a research topic that is unique and new to the readers. This topic may base on the following subject matter: The Child and Adolescent Learners and Learning Principle, History of the English Language, English Syntax, Foundations of English Language Teaching and Learning. Multimodal Communication, Language on Literary Texts, Language on Non-Literary Texts. Furthermore, research instructors are encouraged to introduce the conventional standard in writing research abstracts either based on Hyland (2000) five move framework or Swales' CARS Model.

\section{REFERENCES}

Abarghooeinezhad, A., \& Simin, S. (2015). Analyses of Verb Tense and Voice of Research Article Abstracts in Engineering Journals, International Letters of Social and Humanistic Sciences, 47, 139-152. 
Al-Khasawneh, Fadi Maher. (2017).A genre Analysis of Research Article Abstracts Writtem by Native and Non-Native Speakers in English, Journal of Applied Linguistics and Language Research, 4(1), 1-13

Behnam, B., \& Golpour, F. (2014). A genre analysis of English and Iranian research articles abstracts in applied linguistics and mathematics. International Journal of Applied Linguistics and English Literature, 3(5), 173-179.

Bhatia, V. K. (1997). Introduction: Genre analysis and world Englishes. World Englishes, 16(3), 313-319.

Candarh, D. (2012). A cross-cultural investigation of English and Turkish research article abstracts in Educational Sciences. Studies about Language, 2, 12-17.

Fauzan, U., Lubis, A. \& Kurniawan, E. (2020). Rhetorical moves and linguistic complexity of Research article abstracts in international Applied Linguistics journals, The ASIAN ESP Journal, 16(5.2), 219 - 247.

Ge, D. M., \& Yang, R. Y. (2005). A genre analysis of research article abstracts. Modern Foreign Languages, 28(2), 38-46.

Habibi, Pejman. (2008).Genre Analysis of Research Article Introductions across ESP, Psycholinguistics, and Sociolinguistics. IJAL, 11(2).

Hyland, K. (2000). Disciplinary discourses: Social interactions in academic writing. London, UK: Longman.

Kosasih, Fauzy R., (2018). A Genre Analysis of Thesis Abstracts at a State University in Banten, Lingua Cultura, 12 (1), 9-14. https://doi.org/10.21512/lc.v12i1.1963

Li, Y. (2011). A genre analysis of English and Chinese research article abstracts in Linguistics and Chemistry. Published Master's thesis. San Diego University.

Lorés, R. (2004). On RA abstracts: From rhetorical structure to thematic organization, English for Specific Purposes, 23(3), 280-302.

Magno, J., Mangompit, R. \& Cacha, S. (2020). Graduate theses' rhetorical moves in the introduction and methodology sections. Central Mindanao University Journal of Science, 24(1), 44-60.

Marefat, H., \& Mohammadzadeh, S. (2013). Genre analysis of literature research article abstracts: A cross-linguistic, cross-cultural study. Applied Research on English Language, 2(2), 37-50.

Mohammadi Darabad, Ali. (2016). Move Analysis of Research Article Abstracts: A Cross-Disciplinary Study, International Journal of Linguistics, 8, 125. 10.5296/ijl.v8i2.9379.

Pho, P. D. (2009). An evaluation of three different approaches to the analysis of research article abstracts. Monash University Linguistics Papers, 6(2), 11-16.

Rochma, A. \& Triyono, S. (2019). A discourse analysis: Cohesion of the introduction section of research articles, Journal of English Language Teaching and Linguistics, 4(1), 1-19.

Samraj, B. (2005). An exploration of a genre set: Research article abstracts and introduction in two disciplines. English for Specific Purposes, 24(2), 141-156. 
Runalyn O. Arnaiz, et al

Santos, M. B. D. (1996). The textual organization of research paper abstracts in $\begin{array}{lllll}\text { applied } & \text { linguistic. } & \text { Text, } & 16 & \text { (4), }\end{array}$ http://dx.doi.org/10.1515/text.1.1996.16.4.481

Zhen ye, Ning, (2008). A genre-based analysis of English research article abstracts and the linguistic feature of personal pronouns for financial economics. USChina Education Review, 5, 7. 